\title{
Homing in green turtles Chelonia mydas: oceanic currents act as a constraint rather than as an information source
}

\author{
Charlotte Girard $^{1}$, Joël Sudre ${ }^{2}$, Simon Benhamou ${ }^{3, *}$, David Roos $^{4}$, Paolo Luschi ${ }^{5}$ \\ ${ }^{1}$ Institut de Recherche pour le Développement, Centre de la Réunion, BP 172, 97492 Sainte Clotilde, La Réunion, France \\ ${ }^{2}$ Laboratoire d'Études en Geophysique et Océanographie Spatiales, CNRS, 18 av. Edouard Belin, 31401 Toulouse Cedex 9, France \\ ${ }^{3}$ Centre d'Écologie Fonctionelle et Évolutive, CNRS, 1919 route de Mende, 34293 Montpellier Cedex 5, France \\ ${ }^{4}$ Ressources Halieutiques, IFREMER, BP 60, 97822 Le Port, La Réunion, France \\ ${ }^{5}$ Dipartimento di Biologia, University of Pisa, 6 via Volta, 56126 Pisa, Italy
}

\begin{abstract}
As open sea navigators, green turtles Chelonia mydas have to deal with oceanic currents. These currents may have a mechanical influence, forcing turtles away from their desired course, but they may also provide information to navigating turtles by bringing chemical cues downcurrent from their target area. In the present paper, we have introduced new path analysis methods, coupling remote-sensing oceanographic data and satellite-tracking data in order to test these hypotheses. These methods were exemplified on the homing routes of 3 green turtles nesting on Europa, an isolated island in the southern part of Mozambique Channel. The turtles, displaced by ship east-southeast from Europa, returned to their nesting island in 13 to $59 \mathrm{~d}$, following long, circuitous routes, and hence apparently displaying poor navigational abilities. Path analysis showed that turtles were unable to compensate for the deflecting action of currents, which moved them away from their intended course and lowered their orientation performance. At large distances from Europa, green turtles did not appear to find navigational information in water masses that had previously been in contact with their target area.
\end{abstract}

KEY WORDS: Current drift $\cdot$ Homing $\cdot$ Navigation $\cdot$ Oceanography $\cdot$ Satellite telemetry $\cdot$ Sea turtle

\section{INTRODUCTION}

Sea turtles migrate for hundreds or thousands of kilometres between their foraging grounds and their nesting sites (Papi \& Luschi 1996, Lohmann et al. 1999). During these migrations in the open sea, oceanic currents are likely to influence turtles' movements (Luschi et al. 2003), but the way they affect turtle navigational efficiency is very poorly understood. First, oceanic currents play an obvious mechanical role. The force that currents exert on a turtle resolves into a forward-backward (body-axis aligned) component, which speeds up or slows down the turtle, and a lateral component, which tends to make it drift away from the intended route. This deflecting action may be particularly harmful by leading turtles away from the optimal route. Oceanic currents may also act as an information source providing navigational clues. Green turtles migrating from Brazil to Ascension Island, for instance, have been hypothesised to find their way thanks to a water-borne chemical plume downstream of the goal island (Koch et al. 1969), although homing experiments specifically conducted on Ascension turtles (Luschi et al. 2001) did not confirm this hypothesis.

To fully understand the mechanical action of the currents, it is worth distinguishing between 2 different, independent but complementary ways of dealing with the passive displacement they induce. The first way, which applies to any passive displacement (including 


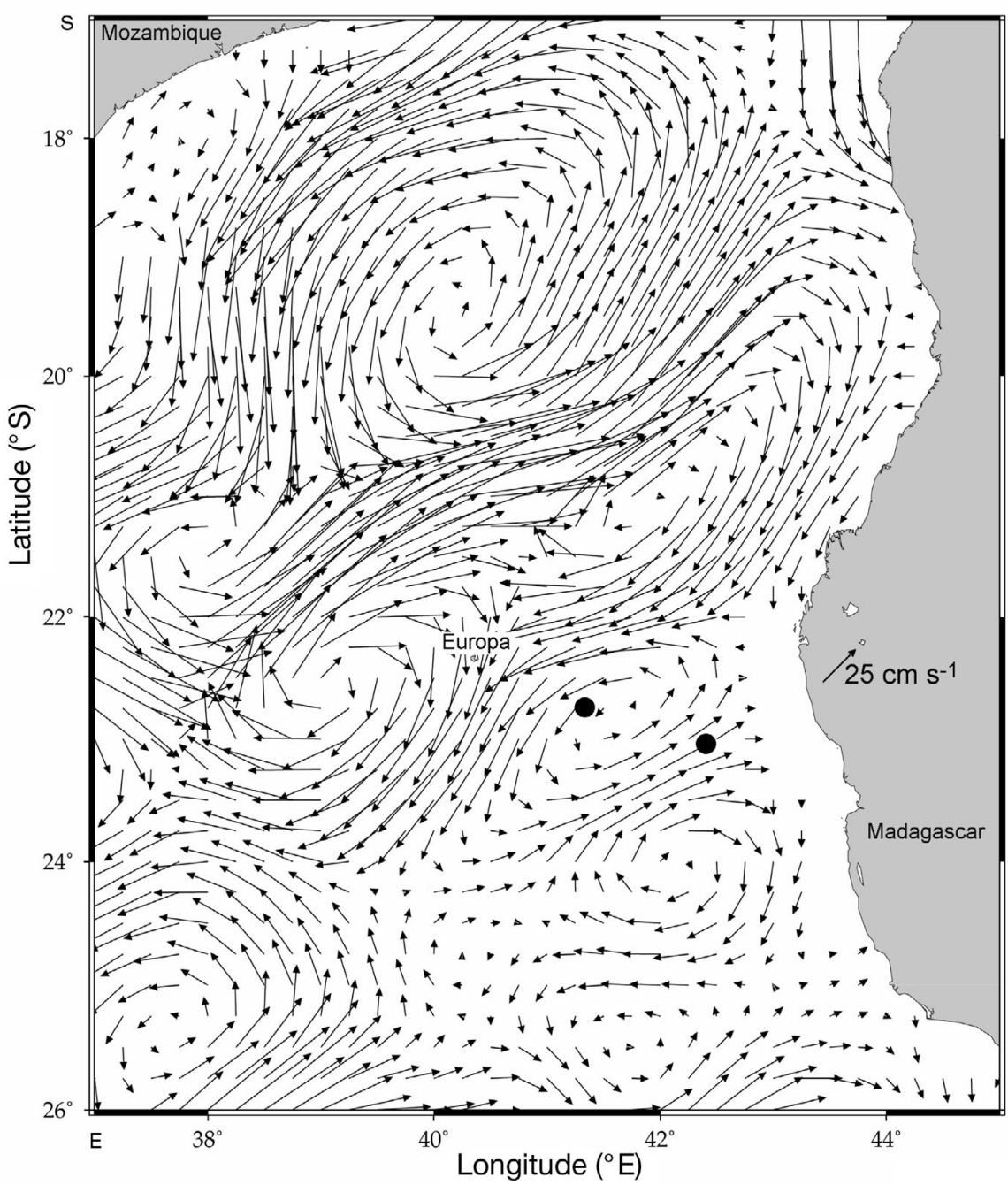

Fig. 1. Surface oceanic currents in the southern part of the Mozambique Channel, $4 \mathrm{~d}$ after release of turtles (Chelonia mydas). At this time, surface currents around Europa were mainly generated by 2 cyclonic eddies (low sea level anomalies, which turn clockwise in the southern hemisphere) to the northeast and the southwest of the island, and by an anticyclonic eddy to the southeast (- release sites)

0.7 speed ratio should head northwestward to maintain its track northward. In other words, displacement correction involves the ability to correctly estimate the goal direction from any location, whereas drift compensation involves the ability to head in a shifted direction, in order to get a resultant direction corresponding to the estimated goal direction. If an animal is able to both correct and compensate, it should adopt headings that are less homeward oriented than the resultant track. Conversely, a homeward tendency that is more accurate for headings than for the track would indicate correction without compensation. In the absence of ground features, which are thought to play a key role in wind drift compensation for birds migrating over land, testing the ability of a homing pelagic animal to compensate for an oceanic current drift may provide valuable insights about the navigation process used (see 'Discussion').

To investigate how sea turtles moving toward a specific target deal with oceanic currents, we developed new methods of path analysis and exemplified them on the homing paths of 3 female green turtles Chelonia mydas nesting on Europa, a small isolated atoll ( 7 to $8 \mathrm{~km}$ in diameter) located in the middle of the southern Mozambique Channel. This oceanographic area is highly dynamic, being swept by an intermittent train of large anticyclonic eddies (each roughly $200 \mathrm{~km}$ in diameter), leading to a predominant

man-made passive displacement as occurring in homing experiments), rests on the ability of an animal to correct for the displacement. It implies that the animal relies on a location-based navigation process that enables it to orientate toward the goal whatever its own location, rather than on a fixed compass-based direction (e.g. genetically encoded; see Berthold 2003). The second way, which can apply only to passive displacements due to movements of the surrounding medium (air or water), rests on the ability of the animal to compensate for the unwanted drift by adopting a biased heading such that the resultant movement points to the goal (Green \& Alerstam 2002). For example, an animal migrating northward that is aware that it is being exposed to an eastward wind drift with a southward water transport along the African coast (Schouten et al. 2003, Quartly \& Srokosz 2004). In late November 2003, the turtles were displaced away from their nesting island to distant open sea sites, and were tracked by satellite. As this date is early in the nesting season on Europa, the turtles were assumed to be highly motivated to get back to the island to complete their nesting cycle (Luschi et al. 2001). Since the goal of these turtles was a specific isolated island, this homing experiment provided a well-defined reference for the turtles' intended direction and was therefore particularly well suited to test the influence of oceanic currents on sea turtle navigation. In this way, we were able to explore both whether green turtles are able to correct for passive displacement and whether they can, 
in some way, compensate for current drift while moving in the oceanic environment. In addition, we tested whether they obtain useful navigational information from the water masses that have previously been in contact with the target area.

\section{MATERIALS AND METHODS}

Turtles and satellite tracking. Three adult green turtles Chelonia mydas (curved carapace length between 107 and $115 \mathrm{~cm}$ ) were caught by night on a beach on Europa $\left(22^{\circ} 20^{\prime} \mathrm{S}, 40^{\circ} 21^{\prime} \mathrm{E}\right)$, kept in individual wooden crates, and then loaded on a ship to be displaced. During transportation, they were kept shaded and wet. Two turtles were individually released at $115 \mathrm{~km}$ east-southeast of Europa in the afternoon, and the third one was released at $245 \mathrm{~km}$ in the same direction by night. They were equipped with Argos satellite transmitters (Telonics ST-20), attached to the carapace with fibre glass cloth and epoxy resin. Location data were filtered out as follows. First, Argos locations of poorest quality (Class B) were discarded. The speed between successive remaining locations was computed, and locations leading to values $>10 \mathrm{~km}$ $\mathrm{h}^{-1}$ were discarded. Afterwards, filtered locations were 'standardised' as a fix every $4 \mathrm{~h}$ by linear time interpolation. In this way, for each turtle, we obtained a ground-related 'track path' in the form of a sequence of purely spatial track vectors that join any given location and the location occurring $4 \mathrm{~h}$ later. lated from surface topographic slope anomalies, which were derived from altimetric sea level anomalies issued from the combined processing of TopexPoseidon and ERS-1/2 data (Ducet et al. 2000), available weekly on a $1 / 3^{\circ}$ Mercator projection grid. The Ekman component, resulting from the balance between friction by wind and the Coriolis force, was estimated for the surface layer (15 $\mathrm{m}$ depth) by applying a regression model (Van Meurs \& Niiler 1997, Lagerloef et al. 1999) on weekly wind stress data provided by Quikscat on a $1 / 2^{\circ}$ regular projection grid. Both geostrophic and wind stress data underwent a bi-linear spatial interpolation, leading to $1 / 4^{\circ}$ velocity fields, and then a time linear interpolation to obtain such fields on a daily basis.

Turtle movement analysis with respect to currents. For each turtle's interpolated location, we computed 3 velocities: (1) the track velocity, obtained by dividing the purely spatial track vector by 0.144 (to convert $\mathrm{km}$ to $\mathrm{cm} \mathrm{s}^{-1}$ ); (2) the current velocity, calculated by spatial bi-linear interpolation at the turtle's location of the daily surface current fields derived from the computations previously described; and (3) the heading velocity, computed as the difference between the track and current velocities (Fig. 2), which thus expresses the turtles' actual forward movement. By removing the current movement component in this way, we obtained a water-related 'motor path' in the form of the sequence of purely spatial heading vectors (obtained by multiplying the heading velocities by 0.144 ) from each turtle's ground-related track path.

Oceanic currents. As upper-layer dives predominate during oceanic movements of green turtles (Hays et al. 2001), currents experienced by turtles in the open ocean could be estimated based on satellite-derived oceanographic data (Fig. 1). To this end, we computed the surface current velocity as the sum of geostrophic and Ekman components, which are assumed to account for the lowest-order dynamics. They were obtained independently from remote sensing data on sea surface height and wind stress. The geostrophic component, resulting from the balance between the horizontal pressure gradient force and the Coriolis force, was calculated as the sum of the mean surface geostrophic current, estimated from climatological data (Rio \& Hernandez 2004), and the surface geostrophic current anomalies. These current anomalies were calcu-

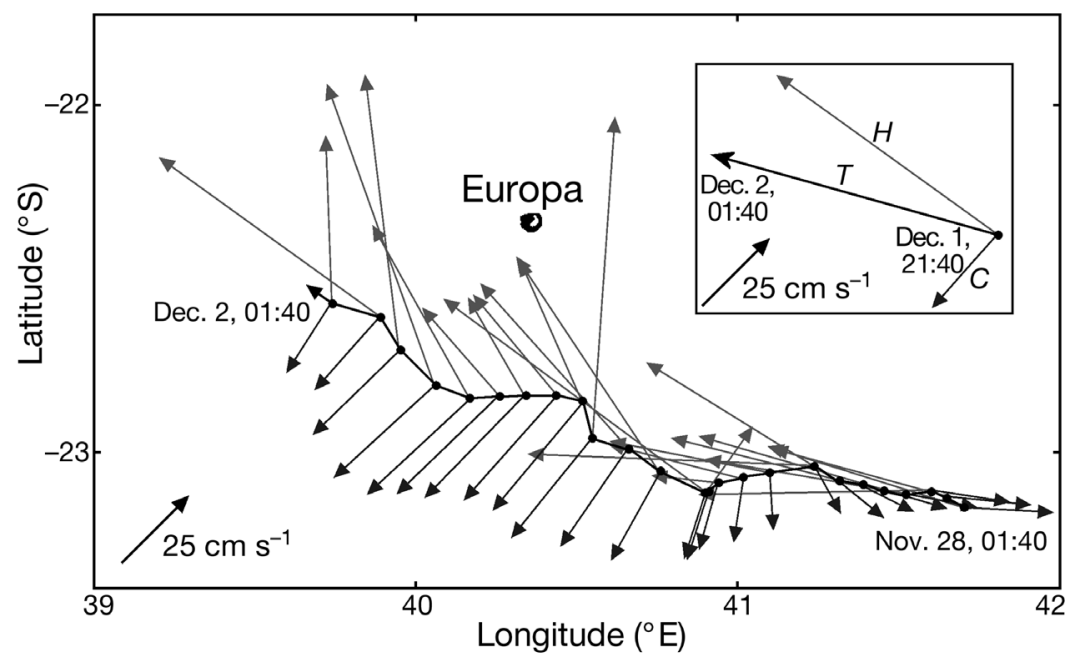

Fig. 2. Chelonia mydas. Section of track path recorded over $4 \mathrm{~d}$ for Turtle T2. (๑): turtle's location every $4 \mathrm{~h}$; dark and light grey vectors are current $(C)$ and heading $(H)$ velocities, respectively, scale given by $25 \mathrm{~cm} \mathrm{~s}^{-1}$ vector length; spatial track path scale given by latitudes $\left(1^{\circ} \approx 111.12 \mathrm{~km}\right)$. Inset illustrates principle of heading vector determination, exemplified by final $4 \mathrm{~h}$ step of this track path section. Heading velocity $\left(\mathrm{cm} \mathrm{s}^{-1}\right)$ is computed by subtracting current velocity $\left(\mathrm{cm} \mathrm{s}^{-1}\right)$ from track velocity $T$ (black vector; $\mathrm{cm} \mathrm{s}^{-1}$ ), obtained by dividing track vector $(\mathrm{km})$ by 0.144 
To measure the orientation efficiency and to test whether the turtles compensated for the current drift, we measured the heading and track 'homeward components' as the cosines of the angular differences between the home direction and the directions of the heading and track vectors, respectively. This was done in 2 different ways. (1) The orientation efficiency of a homing path $(O)$ can be reliably estimated as the average of the homeward components measured along the path at a very high spatial frequency (see Benhamou 2004). This applies to 'track paths' $\left(O_{\mathrm{t}}\right)$ as well as to 'motor paths' $\left(O_{\mathrm{m}}\right)$. The value obtained for a track path is also equal to the ratio of the beeline distance from the release site to the home over the total path length (straightness index), but this practical proxy is not suitable for motor paths, because the goal location is fixed in the ground-related system of reference but not in the water-related system of reference. In practice, the motor and track paths were rediscretised with a small constant step length $l(l=1 \mathrm{~km}$ in the present study) and, hence, appear as sequences of $s$ steps with orientation $\theta_{i}$, for $i=1,2 \ldots s$, starting at location $\left(x_{0}, y_{0}\right)$ and ending at location $\left(x_{S}, y_{s}\right)$. The orientation efficiency was then computed as $O=$ $\sum_{i=1}^{S} \cos \left(\theta_{i}-\gamma_{i-1}\right) / s$, where $\gamma_{i}$ is the goal direction at location $\left(x_{i}, y_{i}\right)$. (2) To test for possible drift compensation, we computed the track and heading homeward components at locations in $4 \mathrm{~h}$ intervals when the current speed was $>25 \mathrm{~cm} \mathrm{~s}^{-1}$. Measuring successive movement vectors of an oriented path, however, may result in autocorrelated angular values because of some forward persistence propensity (Benhamou 2006). Although this autocorrelation does not tend to bias the mean value obtained in the long term, it artificially increases the apparent sample size and hence may lead to erroneous rejections of the null hypothesis. Since autocorrelation obviously decreases when the locations involved become more spaced out, we sub-sampled the data by taking only one measurement every $n$ locations into account, where $n$ is the minimum integer value allowing for statistically independent directions for both heading and track vectors expressed relative to Europa direction (using an angular rank correlation test set at $p=0.10$; see Batschelet 1981). We then compared the heading and track homeward components obtained for each turtle using Wilcoxon signed ranks test. If a turtle were compensating for the current drift, she should have adopted biased headings such that the resultant movement (track) pointed to Europa: in such a case the mean homeward component should be significantly higher for track vectors than for heading vectors. Conversely, a mean homeward component significantly lower for track vectors than for heading vectors would indicate no drift compensation.
Turtle heading analysis with respect to water mass origin. Finally, to determine whether oceanic currents may have been an information source, we examined whether our turtles headed preferentially upcurrent at locations where the water masses had previously been in close contact with Europa. To estimate the origin of the surface water mass surrounding the turtles' locations, 100 evenly spaced virtual drifters were released in a $1 / 8^{\circ}$ side 'square' $(13.9 \times 12.9 \mathrm{~km})$ centred on each turtle's location. Their backward movements for the 30 previous days were simulated on an hourly basis from the 2-dimensional surface velocity field of the area. As surface water masses did not converge or diverge in the area during the tracking period, the vertical velocity component (upwelling or downwelling) was negligible. Consequently, the drifters were likely to be moved by a unique surface water mass and therefore to indicate its origin reliably. Turtles' locations were sorted into 2 groups based on the number of virtual drifters that had been within $20 \mathrm{~km}$ of Europa at any time during the previous 30 days: locations not connected to Europa, with 0 drifters $\left(L_{0}\right)$ and locations strongly connected to Europa, with $>50$ drifters $\left(L_{50}\right)$. The remaining group, which contained only a few locations with intermediate scores, was discarded to compare turtles' locations with a maximum contrast.

For each $L_{0}$ or $L_{50}$ location, we computed the 'currentward component' as the cosine of the angular difference between the heading and current vectors at this location. We sub-sampled these locations in a similar way as explained above to obtain statistically independent angular values (at $\mathrm{p}=0.10$ ), and compared the mean currentward components obtained at the 2 types of locations by a Mann-Whitney test (see Batschelet 1981 for the rationale of this test). If the island generated any water-borne cues useful for navigation, the turtles would have headed upcurrent (negative mean currentward component) at $L_{50}$ locations, and headed at random (null mean currentward component) at $L_{0}$ locations. We can therefore expect a significant difference at these 2 types of locations in the turtles' orientation behaviour with respect to the current direction.

\section{RESULTS}

\section{Homing and orientation efficiency}

The 3 displaced turtles (Chelonia mydas) were not able to relocate Europa quickly, and homed only after having performed circuitous movements, over short (T1), medium (T2), or long (T3) ranges (Fig. 3). Turtles T1 and T2, released $115 \mathrm{~km}$ from Europa, homed in 13 and $21 \mathrm{~d}$, travelling 590 and $1435 \mathrm{~km}$, respectively. Turtle T3, released $245 \mathrm{~km}$ from Europa, homed in 
$59 \mathrm{~d}$, travelling $3515 \mathrm{~km}$. After moving to the west, she performed 2 clockwise followed by 2 anticlockwise loops in the southwest of Europa, and finally reached the island after a $60 \mathrm{~km}$ final leg. All turtles were clearly motivated to return to their nesting island: indeed, none of them showed any tendency to move toward their feeding grounds located along the Madagascar or Mozambique coast (Le Gall \& Hughes 1987). Being herbivorous, adult green turtles do not find suitable food in the open ocean (Bjorndal 1997), so that the circuitous homing routes observed are unlikely to correspond to foraging activity. For each turtle, the track (ground-related) orientation efficiency was quite low, but the heading (waterrelated) orientation efficiency was somewhat higher (Table 1). From all locations, turtles tended to move toward Europa rather than in a fixed direction, so they appeared to be able to correct for the various passive displacements (initial displacement by boat and subsequent displacements due to currents) to which they were subjected. The low track orientation efficiencies with respect to the heading orientation efficiencies, however, suggest that turtles did not compensate for current drift (see below).

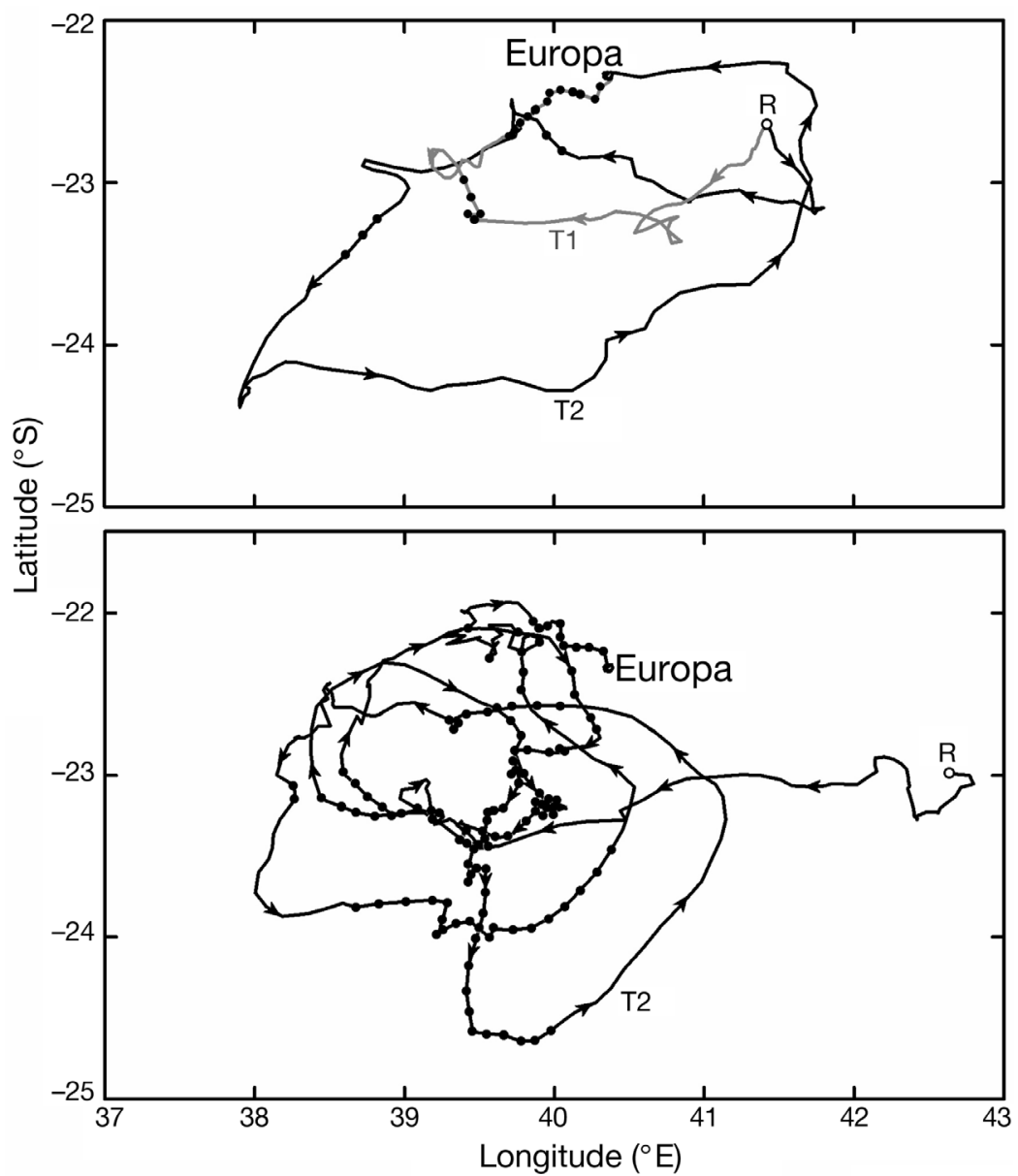

Fig. 3. Chelonia mydas. Tracks of the 3 turtles (T1, T2 and T3) from release sites $\mathrm{R}$ to Europa. Dots along the paths correspond to $L_{50}$ locations, arrows indicate motion direction

\section{Mechanical action of oceanic currents}

In the southern part of the Mozambique Channel, surface velocity currents were mainly due to the geostrophic component, with little contribution due to the Ekman (wind-driven) component. At the beginning of the experiment, the north of Europa was characterised by a large cyclonic eddy, which divided into 2 structures: one to the northeast and the other to the southwest of Europa. They generated a southwest flow of about $30 \mathrm{~cm} \mathrm{~s}^{-1}$ around the island. Turtles were released in a small anticyclonic eddy west-southwest of the island generating weaker currents of about $15 \mathrm{~cm} \mathrm{~s}^{-1}$, which intensified and slowly moved southwest (Fig. 1). During the remaining part of the turtles' journeys, the overall current field around Europa was very variable both in space and time, with cyclonic and anticyclonic eddies appearing and moving through the whole area. On average, however, all 3 turtles experienced oceanic currents that tended to make them drift away from Europa. The mean current speed components on the Europa axis were $-29 \mathrm{~cm} \mathrm{~s}^{-1}$ (T1), $-19 \mathrm{~cm}$ $\mathrm{s}^{-1}$ (T2) and $-22 \mathrm{~cm} \mathrm{~s}^{-1}$ (T3). As turtles moved with a water-related mean speed of $70 \mathrm{~cm} \mathrm{~s}^{-1}$, such a globally upcurrent pattern was likely to reduce their groundrelated mean speed by about $1 / 3$ when they headed toward Europa.

The mean difference $(\Delta H$ in Table 1$)$ between the homeward components of heading vectors and track vectors is significantly higher than zero in Turtle T1 (Wilcoxon $\mathrm{T}+=257, \mathrm{p}<0.001)$, T2 $(\mathrm{T}+=283$, $\mathrm{p}<0.01$ ) and $\mathrm{T} 3(\mathrm{~T}+=1274, \mathrm{p}<0.001)$. In other words, for each turtle, the mean heading direction was significantly closer to the home direction than the mean track direction, in agreement with the previous result about orientation efficiencies. Hence, the turtles did not attempt to compensate for current drift by biasing their heading so as to adjust their track in the home direction. Rather, they appeared to head more or less accurately toward Europa, but the currents made them take other, less efficient paths. 
Table 1. Chelonia mydas. Homing path characteristics. $O_{\mathrm{t}}$ and $O_{\mathrm{m}}$ are orientation efficiencies for track (ground-related) and motor (water-related) paths, $\Delta H$ (mean \pm SEM) is difference between heading and track homeward components measured at locations where current speed was $>25 \mathrm{~cm} \mathrm{~s}^{-1}, C_{50}$ and $C_{0}$ (mean $\pm \mathrm{SEM}$ ) are currentward components for $L_{50}$ and $L_{0}$ locations, $N$ is resulting sample size after sub-sampling and $n$ is sub-sampling integer value used for obtaining statistically independent angular data (i.e. only locations spaced out by minimum $4 \mathrm{n}$ h were considered in analysis)

\begin{tabular}{|lcccrr|}
\hline Turtle & $O_{\mathrm{t}}$ & $O_{\mathrm{m}}$ & $\Delta H(N, n)$ & \multicolumn{1}{c|}{$C_{50}(N, n)$} & $C_{0}(N, n)$ \\
\hline T1 & 0.20 & 0.64 & $0.33 \pm 0.06(23,3)$ & $-0.83 \pm 0.05(19,1)$ & $-0.08 \pm 0.14(23,2)$ \\
T2 & 0.08 & 0.32 & $0.24 \pm 0.08(26,4)$ & $0.02 \pm 0.22(3,2)$ & $-0.33 \pm 0.15(22,5)$ \\
T3 & 0.07 & 0.41 & $0.39 \pm 0.08(53,5)$ & $-0.09 \pm 0.09(71,2)$ & $0.01 \pm 0.15(24,5)$ \\
\hline
\end{tabular}

\section{Analysis of turtles' orientation behaviour}

As the turtles did not compensate for current drift, the heading vectors are better estimates of what they intended to do than the track vectors. The distributions of heading directions expressed relative to the direction of Europa were first sub-sampled (as previously, by taking only 1 measurement every $n$ locations into account, in order to obtain statistically independent angular values at $\mathrm{p}=0.10)$, and then analysed using circular statistics (Batschelet 1981). They differed significantly ( $V$-test at $\mathrm{p}<0.05)$ from a uniform distribution for T1 $\left(r=0.75, \phi=18^{\circ}, N=20, n\right.$ $=4)$, T2 $\left(r=0.37, \phi=-32^{\circ}, N=25, n=5\right)$ and T3 ( $r=$ $\left.0.38, \phi=16^{\circ}, N=71, n=5\right)$. The low values of the mean vector length $r$ (which measures the concentra- tion of the distribution around the mean direction $\phi$ ) obtained in particular for Turtles T2 and T3 indicate, however, that a large amount of random noise was involved. The value of $\phi$ differed significantly from $0^{\circ}$ (Europa direction) only for T1 $(0.01<\mathrm{p}<0.05$; tests based on charts, in Batschelet 1981 p. 86). This suggests some systematic directional bias for this turtle, but there was no global systematic bias. Drawing motor paths (sequences of heading vectors) with respect to Europa direction (Fig. 4) provides a useful representation that clearly shows the tendency of turtles to head toward Europa. Hence, a comparison of the motor and track paths drawn with respect to Europa direction highlights the mechanical impact of currents on the homing journeys of turtles unable to compensate for current drift.
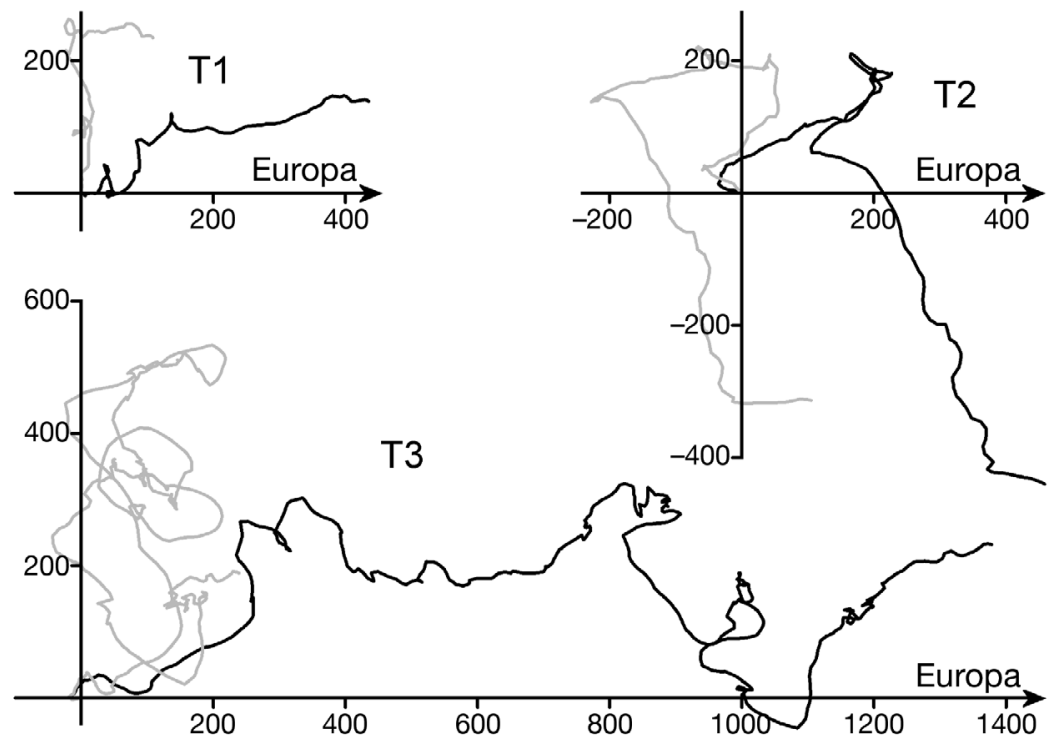

Fig. 4. Chelonia mydas. Motor (water-related; black) and track (ground-related; grey) paths expressed with respect to Europa direction. Axes $X$ (Europa direction) and $Y$ (orthogonal direction) report distance values $(\mathrm{km}): X_{k}=$ $\Sigma_{i=1}^{k} l \cos \left(\theta_{i}-\gamma_{i-1}\right)$ and $Y_{k}=\Sigma_{i=1}^{k} l \sin \left(\theta_{i}-\gamma_{i-1}\right)$, for $k=1,2 \ldots, s$, computed from paths rediscretized as sequences of $s$ steps with orientations $\theta$ and a small constant length $l$. Orientation efficiency $(O)$ corresponds to ratio of the whole home-directed movement component $\left(X_{s}\right)$ over path length $(L=s l)$; $O=\Sigma_{i=1}^{s} \cos \left(\theta_{i}-\gamma_{i-1}\right) / s=X_{s} / L$

\section{Oceanic currents as a possible information source}

For Turtles T2 and T3, there was no significant difference in mean currentward components between $L_{50}$ and $L_{0}$ locations (Table 1; T2: $U=21$, ns; T3: $U=789$, ns). Turtle T2 homed along a final straight segment longer than $100 \mathrm{~km}$, during which she never experienced water that had been in contact with Europa during the previous $30 \mathrm{~d}$. In contrast, T3 homed along a $60 \mathrm{~km}$ long upcurrent final stage. Previously, she had often experienced water masses that had been in contact with Europa, even when she was relatively close to it, but such experience did not lead her to head toward the target. For T1, the headings were significantly more oriented upcurrent at $L_{50}$ locations $(U=72, \mathrm{p}<0.001)$, but most of the $L_{50}$ locations occurred in the last stage (80 km long) of the homing path, when the turtle was moving upcurrent while 
approaching the island. It is worth noting that the mean current directions with respect to Europa direction were similar between $L_{0}$ and $L_{50}$ locations for T2 $\left(156^{\circ}\right.$ versus $\left.150^{\circ}\right)$ and T3 $\left(-166^{\circ}\right.$ versus $\left.-170^{\circ}\right)$, but not for T1 $\left(133^{\circ}\right.$ versus $\left.-165^{\circ}\right)$ : currents were on average more or less opposite to the home direction at any location for T2 and T3, while for T1 the home direction was clearly more upcurrent at $L_{50}$ than at $L_{0}$ locations. The apparent tendency of $\mathrm{T} 1$ to head significantly more upcurrent at $L_{50}$ than at $L_{0}$ locations might, therefore, simply reflect her tendency to head preferentially toward Europa at any location, irrespective of the local current direction.

\section{DISCUSSION}

We aimed to initiate a new approach to the study of sea turtle navigation by looking at the possible effects of oceanic currents in a homing context. To date, the analyses of adult movements with respect to oceanic currents have focused on postnesting migrations (e.g. Luschi et al. 1998, Horrocks et al. 2001). A homing experiment is, however, more liable to provide a clear picture, thanks to a very well-defined goal direction, especially when the goal is a small isolated island like Europa. With a sample size of only 3 turtles, no firm conclusions on the navigational mechanisms at work can conclusively be drawn, although some preliminary inferences can be made.

Oceanic currents certainly act as a mechanical factor, forcing turtles to drift away from the most suitable route. Birds face a similar problem with winds, and appear to compensate for wind drift only over land, in the presence of ground features (e.g. Bäckam \& Alerstam 2001, Green \& Alerstam 2002, Thorup et al. 2003). For example, a bird migrating northward over land may be aware that it is being subjected to an eastward wind drift because of the diverging line between the right and left visual flow hemifields generated by ground features, which should lay north, but is shifted somewhat to the right. In the pelagic environment, where ground features are not available, monitoring drift is much more arduous, because it requires an estimation of the discrepancy between the actual and expected locations. Hence, drift compensation cannot be accomplished by a pelagic animal that relies on a simple navigation process enabling it only to infer the goal direction without being able to determine its own location. However, it might still be possible, if the animal relies on a more sophisticated navigation process enabling it to assess its own location within the environment.

The difference between these 2 types of processes is illustrated in the history of human navigation. Ancient navigators relied on 'dead-reckoning' (known in ani- mals as path integration; review in Benhamou 1997), by which they conjointly estimated the (water-related) speed of the ship using a knotted rope and the course steered with respect to a magnetic compass to infer the distance and direction from the starting harbour. In the absence of ground features, they had no means to compensate for possible leeway (off-course lateral movement induced by currents and winds), and had no means to simply correct for this displacement, because dead-reckoning is a route-based navigation process: it does not allow a seafarer to estimate the actual (ground-related) locations of the ship and the harbour, but only their locations relative to each other (this latter estimation being correct only in the absence of drift). Later, human navigators used a sextant, and very recently the Global Positioning System, to determine their actual location in the open sea. Thus, thanks to a sophisticated location-based navigation process, they became able both to correct for possible displacement due to leeway (i.e. to re-estimate the goal direction at regular intervals) and to compensate for it by adopting a biased heading aimed to reduce the discrepancy between their actual and expected locations. The comparative analysis of location-based navigation in rats and bees (review in Benhamou 1997) also provides an illustration of the different kinds of processes that may be involved in this type of navigation. A rat is known to rely on a kind of map-like system to determine both its own location and its goal location with respect to proximal landmarks. Thus, it can navigate using a landmark-based system of reference, which is functionally similar to a seafarer equipped with a sextant who is navigating according to a celestial-based system of reference. In contrast, a bee is thought to infer the direction of its goal in a much more rigid way, from the discrepancy between the actual retinotopic coordinates of the landmarks and those memorised at the goal location as a snapshot, so without determining its own location. Both rats and bees re-estimate the goal direction at regular intervals, and thus are fully able to correct for possible displacement (in this context, however, even a bee may compensate for wind drift by relying on the visual flow generated by ground features).

It can be hypothesised that sea turtles rely on a 'map and compass' process based on intersecting gradient fields (see Benhamou 2003, Wiltschko \& Nehmzow 2005 for recent accounts on this concept). Contrary to what its name suggests, this process does not necessarily refer to sophisticated map-based navigation, but can take 2 forms. In the simplest form, analogous to the bee's location-based navigation system, the animal is assumed to establish the local home direction based on the differences in gradient field values perceived at its present location and memorised at the home location, without determining its own location. The other, more 
sophisticated form is analogous to the rat's locationbased navigation system. It involves a kind of map-like representation of the environment on which any location can be specified with respect to the environment based on its respective gradient field coordinates. Both solutions enable an animal to correct for any passive displacement (man-made or due to oceanic currents), but only the latter enables it to compensate for current drift, because, in the absence of ground features, a continuous appraisal of drift rests upon the comparison of actual and expected locations, which cannot be achieved by relying on the simplest method. The fact that our homing turtles did not compensate for current drift, although this would have led to better navigational efficiency, suggests that they relied on a simple navigational solution enabling them to move more or less efficiently in the home direction, but not being able to fully assess their own location in the environment.

While displaced turtles eventually managed to get back to their nesting island, they did so with long, winding routes, which may be indicative of poor navigational abilities (see also Luschi et al. 2001). The fact that they headed roughly homeward shows, however, that they actually had some indication of the home direction after passive displacement. Their poor navigational performance suggests that the navigation process at work is noisy and biased, besides not allowing current drift compensation. The tendency of our turtles to bias their initial search toward a location south of Europa is intriguing, being only partly explained through the action of current drift. It may also be caused by a bicoordinate navigational process involving non-orthogonal gradient fields (Benhamou 2003).

Finally, we looked at whether turtles were able to sense some type of additional navigational information brought by water masses that had previously been in contact with their nesting island. This type of information, if at all relevant, should be secondary, as it is available only at particular locations and times, but may enable a turtle to home faster when the circumstances are favourable. Because of diffusion processes, the concentrations of chemical cues in water masses that have previously been in contact with a source decrease progressively along the current mainstream. Hence, turtles could use some elementary orientation mechanism (see Benhamou \& Bovet 1992) to head toward the areas of higher concentration, and therefore indirectly upcurrent, without determining the current's direction, provided the flow turbulence is not too high (Balkovsky \& Shraiman 2002). Although the disparate results obtained prevent definitive conclusions, no such information seems to be available or detected by turtles at large distances from their nesting island, possibly because the cues involved are ephemeral and disappear in a few days. This view is in general accor- dance with the conclusions drawn for Ascension Island green turtles, which were displaced downcurrent and failed to return quickly to their home (Luschi et al. 2001). Nevertheless, as 2 of our 3 turtles moved upcurrent during the final leg of their homing journey, information borne by oceanic currents may have been used when turtles were closer to the island.

The conclusions drawn above should be considered preliminary, because they are based on 3 turtles only. Our data did not allow us to determine which kind of information is used by navigating turtles, but we can at least assume that such information is not likely to be provided by water-borne chemical cues issuing from the nesting island. In this paper the methodological implications are clearly our most important contribution to the study of sea turtles, as we showed how a new path analysis approach can be developed by coupling satellite remote-sensing oceanographic data and satellite-tracking data. This approach enables us to distinguish between what the turtles actually did (track paths) and what they intended to do (motor paths), and to determine the origin of the water masses encountered. The representation of both water- and ground-related paths with respect to the goal direction highlights the mechanical impact of oceanic currents on turtles' journeys and makes it possible to estimate the turtles' true orientation efficiency. In the future, special care should be taken to compute motor paths before drawing any conclusions on the orientation behaviour of sea turtles in the open ocean.

Acknowledgements. We are grateful to the Préfet de La Réunion for authorisation to experiment on Europa's green turtles (under S.B.'s French Living Animals Experiment licence No. 34-100), to the French Navy, FAZSOI and DAF (Mayotte) for transport and logistical support, and to M.-H. Rio and F. Hernandez for their estimations of currents in the Mozambique Channel. Altimeter and wind data were obtained from CLS Space Oceanography Division, as part of the Environment and Climate EU Enact project, with support from CNES, and from CERSAT (IFREMER Plouzané), respectively. C.G. acknowledges La Région Réunion for providing her a $\mathrm{PhD}$ grant. Special thanks to L. Dagorn, M. Taquet and F. Papi for their invaluable help.

\section{LITERATURE CITED}

Bäckam J, Alerstam A (2001) Confronting the winds: orientation and flight behaviour of roosting swifts, Apus apus. Proc R Soc Lond Ser B 268:1081-1087

Balkovsky E, Shraiman BI (2002) Olfactory search at high Reynolds number. Proc Natl Acad Sci USA 99: 12589-12593

Batschelet E (1981) Circular statistics in biology. Academic Press, London

Benhamou S (1997) On systems of reference involved in spatial memory. Behav Proc 40:149-163

Benhamou S (2003) Bicoordinate navigation based on nonorthogonal gradient fields. J Theor Biol 225:235-239 
Benhamou S (2004) How to reliably estimate the tortuosity of an animal's path: Straightness, sinuosity, or fractal dimension? J Theor Biol 229:209-220

Benhamou S (2006) Detecting an orientation component in animal paths when the preferred direction is individualdependent. Ecology 87:518-528

Benhamou S, Bovet P (1992) Distinguishing between elementary orientation mechanisms by means of path analysis. Anim Behav 43:371-377

Berthold P (2003) Genetic basis and evolutionary aspects of bird migration. Adv Study Behav 33:175-229

Bjorndal KA (1997) Foraging ecology and nutrition of sea turtles. In: Lutz PL, Musick JA (eds) The biology of sea turtles. CRC Press, NewYork, p 199-231

Ducet N, Le Traon PY, Reverdin G (2000) Global high resolution mapping of ocean circulation from TOPEX/Poseidon and ERS-1 and -2. J Geophys Res Oceans 105: 19477-19498

Green M, Alerstam T (2002) The problem of estimating wind drift in migrating birds. J Theor Biol 218:485-496

Hays GC, Åkesson S, Broderick AC, Glen F and 5 others (2001) The diving behaviour of green turtles undertaking oceanic migration to and from Ascension Island: dive durations, dive profiles and depth distribution. J Exp Biol 204:4093-4098

Horrocks JA, Vermeer LA, Krueger B, Coyne M, Schroeder BA, Balazs GH (2001) Migration routes and destination characteristics of post-nesting hawksbill turtles satellitetracked from Barbados, West Indies. Chelonian Conserv Biol 4:107-114

Koch AL, Carr A, Ehrenfeld DW (1969) The problem of open sea navigation: the migration of the green turtle to Ascension Island. J Theor Biol 22:163-179

Lagerloef GS, Mitchum GT, Lukas RB, Niiler PP (1999) Tropical Pacific near-surface currents estimated from altimeter, wind, and drifter data. J Geophys Res Oceans 104: 23313-23326

Editorial responsibility: Howard I. Browman (Associate Editor-in-Chief), Storebø, Norway
Le Gall JY, Hughes GR (1987) Migrations de la tortue verte Chelonia mydas dans l'Océan Indien Sud-Ouest observées à partir des marquages sur les sites de ponte Europa et Tromelin (1970-1985). Amphib-Reptilia 8: $277-282$

Lohmann KJ, Hester JT, Lohmann CM (1999) Long-distance navigation in sea turtles. Ethol Ecol Evol 11:1-23

Luschi P, Hays GC, Del Seppia C, Marsh R, Papi F (1998) The navigational feats of green sea turtles migrating from Ascension Island investigated by satellite telemetry. Proc R Soc Lond Ser B 265:2279-2284

Luschi P, Åkesson S, Broderick AC, Glen F, Godley BJ, Papi F, Hays GC (2001) Testing the navigational abilities of oceanic migrants: displacement experiments on green sea turtles (Chelonia mydas). Behav Ecol Sociobiol 50:528-534

Luschi P, Hays GC, Papi F (2003) A review of long-distance movements by marine turtles, and the possible role of ocean currents. Oikos 103:293-302

Papi F, Luschi P (1996) Pinpointing 'Isla Meta': the case of sea turtles and albatrosses. J Exp Biol 199:65-71

Quartly GD, Srokosz MA (2004) Eddies in the southern Mozambique Channel. Deep-Sea Res II 51:69-83

Rio $\mathrm{MH}$, Hernandez F (2004) A mean dynamic topography computed over the world ocean from altimetry, in situ measurement, and a geoid model. J Geophys Res Oceans 109:C12032

Schouten MW, de Ruijter WP, Jan van Leeuwen P, Ridderinkhof H (2003) Eddies and variability in the Mozambique Channel. Deep-Sea Res II 50:1987-2003

Thorup K, Alerstam T, Hake M, Kjellén N (2003) Bird orientation: compensation for wind drift in migrating raptors is age dependent. Proc R Soc Lond Ser B (Suppl) 270:8-11

Van Meurs P, Niiler PP (1997) Temporal variability of the large-scale geostrophic surface velocity in the northeast Pacific. J Phys Oceanogr 27:2288-2297

Wiltschko R, Nehmzow U (2005) Simulating pigeon navigation. Anim Behav 69:813-826

Submitted: December 5, 2005; Accepted: February 27, 2006

Proofs received from author(s): August 30, 2006 